\title{
Review of Environmental Risk Management in South Africa
}

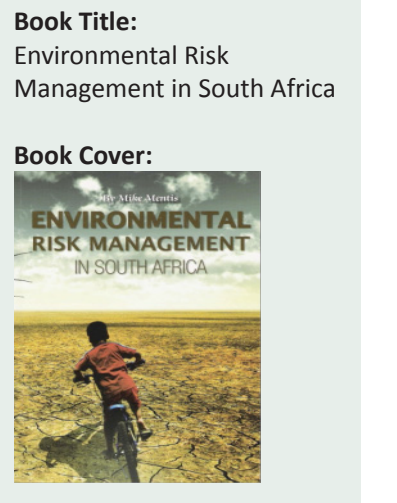

Author:

Mike Mentis

ISBN:

9780620507523

Publisher:

Publisher.co.za; 2010,

R228.00*

*Book price at time of review

-

Review Title:

Review of Environmental

Risk Management in

South Africa

Reviewer:

Harry Biggs ${ }^{1}$

Affiliation:

${ }^{1}$ SANParks, Skukuza,

South Africa

Email:

biggs@sanparks.org

Postal address:

Private Bag X402, Skukuza

1350 , South Africa

How to cite this book review:

Biggs, H., 2011, 'Review of Environmental Risk

Management in South Africa', Koedoe 53(1), Art. \#1065,

1 page. doi:10.4102/koedoe. v53i1.1065

(C) 2011. The Authors. Licensee: OpenJournals Publishing. This work is licensed under the Creative Commons Attribution License.
Congratulations to Mike Mentis on producing such a concise, clear and powerful guide and critique! I would recommend this book to any environmental manager or consultant who is seeking something beyond the largely once-off and routinised processes in use in South Africa for Integrated Environmental Management (IEM) especially if they have an existing or potential interest in a more adaptive, risk-based approach. I would also hope that open-minded officials responsible for the legislation he criticises, would give the arguments put forward in the book a fair hearing.

For active practitioners, the book is useful because it uses 'risk' as the central notion to improve on what was probably all along intended by the word 'impact'. This is convincingly justified in the course of the book. Many practitioners will have heard of, or even used some components of risk-based techniques. However, I believe that the steps and techniques that he clearly lays out, provide the necessary bridge from a more conventional EIA to a much improved EIA - with a central emphasis on adaptation and risk analysis. These approaches can also be used in wider environmental contexts. In fact I wondered whether we are not eventually getting to the point that so-called 'ecosystem management' will at last, in actual practice, be seen in a stronger continuum with 'environmental management', the latter usually understood in the sense of dealing with consequences of 'developments'. I always found it curious that 'ecosystem management' textbooks (and now slowly, ecosystem management practice, at least in some settings) shows far more uptake of the adaptive ethos. Regarding the latter, he makes the point over and over again (rising to a crescendo in the last chapter) that the law's prescriptions, although not excluding this, do very little to encourage a learning approach through iterations - the vast majority of EIAs and environmental management plans produce close to static blueprints. He likens this, amongst other analogies, to a general heading out to war with a full and irrevocable plan written out of his units' movements, intentions and assumed outcomes for the next several years! A semi-independent chapter on decision-making deals with several complementary ideas which add further value to the whole risk theme, but which, again, can be used in many other settings too. These useful principles are not restricted to IEM, though most of his examples are.

Regarding the author's critique of the existing de facto practice of IEM in South Africa as an outflow of the law, the author builds a solid interconnected argument (which I won't spoil for the reader) that a serious re-think is necessary and overdue. This includes the paranoia of omission - the underlying fear of not covering every possible risk in an EIA. If the risks are sensibly prioritised by analysis (one subject of the book) and action restricted, at least initially, to those that have the best chance of delivering, then achieving clearly set environmental goals actually becomes possible. What really locks us into the 'once-off blueprint mode' is the fact that the environmental departments of government, who in good but misguided faith want to control everything centrally, cannot even deal with the 'once-offs', let alone the updates which are actually essential to make the system work properly. He suggests several possible changes to the way the country deals with this, including placing the onus on developers to actually buy into - and defend their reputations based on - the real underlying fundamentals of the Constitution (the right to an environment not harmful to health, free from pollution and degradation) rather than seeing that they as quickly or easily as possible pass the 'tick-box' test of the current EIA requirements. The ultimate changes he suggests need to be radical, but he suggests these could be phased in for workability. Except in a few very small ways, the 2010 regulation changes (which appeared just after his book came out) under the South African National Environmental Management Act, do not move in the directions he proposes. So all those with an interest in robust debate on this topic - this book is also for you!

There are a few minor glitches (some semi-estranged footnotes and some typos/miscalculations in a key decision-tree graphic) but nothing serious enough to do much more than keep the reader on her or his feet. Many messages are repeated over and over again, and the final chapter reads a bit like a sermon. But in my opinion he is close to spot on, and I hope we see practitioners using more of this approach, and ultimately that we see a revamp in South Africa (he does not discuss whether other countries are any better - I fear not - and in which case it is indeed another chance for South Africa to show some leadership). Readers who don't agree with him will grow by at least facing the suggestions and challenges articulated in this highly readable book with its clear examples. My suggestion is to either consider adopting this line of thinking, or to produce something better, but not to let it leave one cold. 